\title{
Tricks of the stage
}

\section{A restored imperial theatre in China reveals how Western techniques of visual perspective brought by the Jesuits were adopted by an eighteenth-century Chinese emperor, explains Martin Kemp.}

Since the invention of linear perspective in the Italian Renaissance, the Western way of representing space - especially in photography - has triumphed worldwide. Westerners have, moreover, tended to regard earlier pictorial cultures that did not discover perspective as deficient. This assumption is unwarranted, as amply demonstrated by the Chinese 'perspective wars' of the eighteenth century.

The battles were fought between Chinese artists and Jesuit missionaries, who also brought Western astronomy to the Qing court. Chinese astronomers had long had a command of sophisticated geometrical and instrumental techniques. However, the astronomical methods of the Jesuits, especially those of the Flemish mathematician Ferdinand Verbiest, found favour with successive emperors because their predictions tended to be more accurate (see Nature 454, 405; 2008). Much the same happened with the perspectival techniques in which the Jesuits specialized, although these were contested by Chinese artists at the time because they ran contrary to the freer modes of spatial representation in Chinese art.

The key Jesuit participant in the artistic battles was Giuseppe Castiglione (1688-1766). He trained as a painter in Milan, was ordained in 1709 and was dispatched to China as a missionary in 1715. Settling in Beijing, he won favour with the emperor Qianlong, and forged a successful career as a painter and architect. He teamed up with the Chinese scholar Nian Xiyao to write a book on the optical perspective of painting in the Western manner, the Shixue (Visual Learning), published in 1729 with an expanded edition in 1735. Their methods were based on the magnificent Perspectiva pictorum et architectorum of 1693 by the Roman painter and designer Andrea Pozzo, but the treatise is far
"There was resistance to this Westernized court trickery."

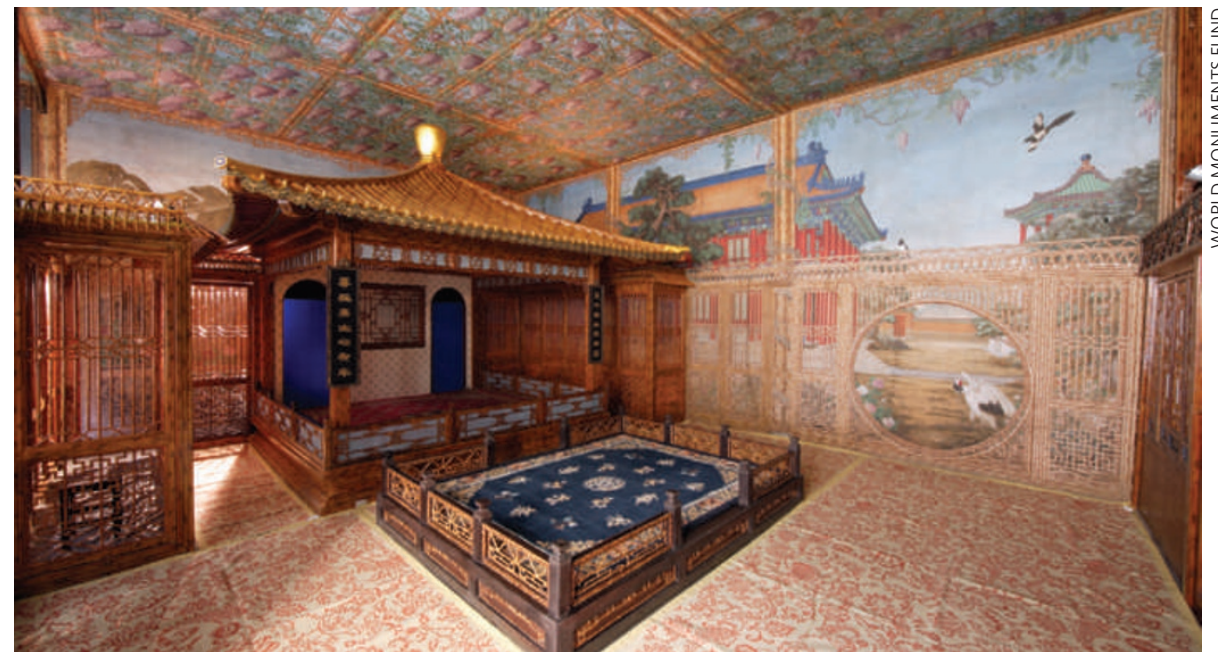

The wall painting in Emperor Qianlong's retirement palace follows Western geometric prescriptions.

for life after his intended abdication, he planned a Palace of Tranquillity and Longevity for his personal delectation. It occupied a modest hectare within the 70 or so hectares covered by the Royal Palace. Qianlong, who was also a prolific poet, was never to retreat wholly to the new palace after his abdication in 1796, preferring to keep a close eye on his successor. However, no effort was spared on the planned enclave.

Among its delights is a compact theatre in the Studio of Exhaustion from Diligent Service, designed for the performance of chaqu, a form of opera, which Qianlong could watch privately from his secluded throne. The decoration of the theatre, newly restored, is the most effective and charming example of Castiglione's techniques of illusionistic perspective, although apparently carried out by disciples after his death in 1766.

Entering from the side through a circular aperture in a bamboo screen, the emperor was prefrom a work of slavish derivation and includes original geometrical demonstrations.

Chinese geometers of the time possessed techniques that were sufficient to master perspectival projection once they saw a reason for doing so. For his part, Castiglione (whose Chinese name was Lang Shining) strove with considerable success to absorb the special methods of indigenous painting. He achieved a blend of Chinese and Western styles that largely avoided looking like an uneasy hybrid.

When emperor Qianlong (who reigned from 1736 to 1795 ) began in 1771 to prepare sented with an inviting view of garden pavilions through a matching screen painted with intricate skill (pictured). Trees, flowers and birds inhabit the painted grounds in which the pavilions are set, while overhead is a delightful bower of fictive bamboo and hanging grapes. The perspectival view on the wall was not, however, a setting for the performance, which occurred in a low pavilion to its left. The illusion is pure entertainment.

The carefully planned illusion, which works perfectly from a specific viewpoint within the room, is in theory vulnerable if viewed from less favourable positions. But the interruptions created by the screen, which break the perspective into a series of relatively discrete motifs, help to minimize the potential problems. Castiglione had taught the theory and practice of perspective very well.

Yet there was resistance to this kind of Westernized court trickery among Chinese connoisseurs. Zou Yigui (1686-1772), a noted painter of flowers and birds, was particularly severe in his criticism. He acknowledged that "the Westerners are skilled in geometry", and explained how "when they paint a scene, the perspective is represented from broad to narrow, calculated mathematically. Their mural paintings depicting palaces look so real that one is almost tempted to walk into them." But he saw the foreign style as "completely deficient in the mastery of the brush. All we see with such art is nothing but craftsmanship, and [it] cannot therefore be clas-

The basis for such condemnation lay in the long Chinese tradition of hard-won skill in the supreme art of calligraphy and in landscape painting in ink. The Chinese artist's hands and eyes aspire to a refined freedom in conveying what is spiritually contemplated rather than what is mechanically seen. Calligraphers and painters practised arts that were philosophical and poetic rather than dominated by the calculated mechanics of Western naturalism. Even in present-day China, the dust of these ancient battles has still not settled.

Martin Kemp is emeritus professor in history of art at the University of Oxford, Oxford, UK. sified along with paintings of quality." 